\title{
The Endocrine Origin and Different Characters of Breast Cancers - Recent Research on Hormone Receptors and Endocrine Treatment*
}

\author{
Peter Dubsky Michael Gnant \\ Department of Surgery, Medical University of Vienna, Austria
}

\section{Key Words \\ Breast cancer - Estrogen receptor - Progesterone receptor - Antiestrogens - Aromatase inhibitors}

\section{Summary}

This report from the San Antonio Breast Cancer Symposium 2005 (SABCS 2005) outlines recent research pertaining to the origins of breast cancer and its translational, clinical and therapeutic consequences. In its first part, recent data concerning the origins of hormone receptors will be discussed. Presentations by 3 of the leading researchers in the field given during a minisymposium show that breast cancer is not a homogenous disease. In individual patients and within individual tumors, phenotypic and genotypic variety is present, posing a scientific challenge and the probable source of failure for the usually uniform treatment options used today. Furthermore, the characterization of different tumor cell subtypes and their respective origin may produce knowledge that can form the basis for new treatment modalities. Interestingly, tumor cells appear to maintain their principal molecular subtype throughout their transformation from earlier non-invasive and premalignant lesions, providing future potential for early detection and intervention. The molecular origin of different breast cancer subtypes may also affect epidemiologic data and therapeutic strategies. In the second part of this report, selected poster presentations on endocrine therapy, spectacular research about receptor signaling, molecular pathways and the biological implications of current treatments are summarized.

*A review of selected presentations and posters presented at the 28th Annual San Antonio Breast Cancer Symposium - December 8-11, 2005

\author{
Schlüsselwörter \\ Brustkrebs · Österogenrezeptor · Progesteronrezeptor . \\ Antiöstrogene - Aromataseinhibitoren
}

\section{Zusammenfassung}

Der vorliegenden Bericht über das San Antonio Breast Cancer Symposium 2005 (SABCS 2005) umreißt die neueste Forschung über den Ursprung von Brustkrebs und die translationellen, klinischen und therapeutischen Konsequenzen. Im ersten Teil werden aktuelle Forschungsergebnisse über den Ursprung von Hormonrezeptoren besprochen. Die Thematik wurde von 3 führenden Forschern innerhalb eines Minisymposiums behandelt. Es wird hervorgehoben, dass Brustkrebs keine einheitliche Erkrankung darstellt. Sowohl zwischen individuellen Patientinnen als auch innerhalb einzelner Tumoren besteht große phänotypische und genotypische Variabilität, was eine wissenschaftliche Herausforderung und die anzunehmende Ursache von Therapieversagen unserer üblicherweise uniformen Behandlungsmodalitäten darstellt. Durch die Charakterisierung der verschiedenen Tumorzellsubtypen und ihres jeweiligen Ursprungs können Informationen gewonnen werden, die die Grundlage für neue Behandlungsmodalitäten bilden können. Interessanterweise scheinen Tumorzellen ihr molekulares Profil während der Umwandlung von den früheren non-invasiven und prämalignen Formen beizubehalten, was in der Zukunft ein Potential für frühe Diagnose und präventive Intervention darstellen könnte. Der molekulare Ursprung der unterschiedlichen Brustkrebsformen kann auch epidemiologische Daten und therapeutische Strategien in neuem Licht erscheinen lassen und beeinflussen. Im zweiten Teil des Berichtes wird auf ausgesuchte Posterpräsentationen über endokrine Therapie, Aufsehen erregende Forschungsergebnisse über den molekularen Funktionsmechanismus der Rezeptoren und die biologischen Implikationen für gegenwärtige Behandlungsstrategien eingegangen.

\begin{tabular}{ll}
\hline KARGER & @ 2006 S. Karger GmbH, Freiburg \\
Fax +49 761 4520714 & Accessible online at: \\
$\begin{array}{l}\text { E-mail Information@Karger.de } \\
\text { www.karger.com }\end{array}$ & www.karger.com/brc \\
&
\end{tabular}

Prof. Dr. med. Michael Gnant

Medizinische Universität Wien, Universitätsklinik für Chirurgie

Austrian Breast und Colorectal Cancer Study Group

Währinger Gürtel 18-20, 1090 Wien, Austria

Tel. +43 1 40400-5646, Fax -6807

E-mail michael.gnant@meduniwien.ac.at 


\section{The Origins of Estrogen Receptor-Positive and -Negative Breast Cancer}

Ovarian steroids acting through nuclear receptors are pivotal in the growth of breast tissue and the development of breast cancer. Most importantly, tumors are often dependent on the presence of estrogen in their environment, thus pointing out a broad range of therapeutic targets. In recent years, several genes and protein isoforms of the estrogen receptor (ER) and the progesterone receptor $(\mathrm{PgR})$ have enabled us to discover their biologic role in the transition from normal breast tissue to invasive breast cancer (IBC). The tumorigenesis of the breast may have several important contributions stemming from the ER and its interaction with multiple signaling pathways. Research on the origins of ER in breast cancer is a promising field shedding light on breast cancer biology in a way that could enable better prediction and closely targeted therapy.

At the 28th Annual San Antonio Breast Cancer Symposium 2005 (SABCS 2005), a minisymposium moderated by Craig Allred, PhD and Jenny Chang, MD (both from Baylor College of Medicine, Houston, TX, USA) challenged its presenters to answer questions pertaining to breast cancer cell precursors, development and subtypes, and the prediction of response to current endocrine therapies. Furthermore, there was considerable interest in targeting novel signaling pathways, especially growth factor pathways interacting with ER signaling. Robert Clarke, PhD (University of Manchester, Manchester, UK) presented material showing the origin of $\mathrm{ER} \alpha$ on both normal breast tissue and IBC and its precursors. Normal breast cancer tissue develops from multipotent stem cells differentiating into both luminal epithelial and myoepithelial cells. A similar model may apply to breast cancer and has gained considerable support in the literature [1,2]. Malignant tissue shows hierarchical organization including a putative stem cell compartment for its renewal that could have accumulated the mutations leading to invasive cancer. The phenotype of cancerous tissue may thus depend on the phenotype of its precursor, a model that has previously been illustrated in leukemia.

Stem cells from normal breast tissue can be obtained using several methods. Dr. Robert Clarke presented data showing the isolation of putative stem cells using a fluorescence-activated cell sorting (FACS) method. A thorough review of the mammary gland side population obtained by its ability to pump out Hoechst 33342 dye has been published [3] as has data from Clarke's group on putative stem cell markers obtained by several complementary approaches [4]. In summary, the data suggests that undifferentiated cells with clonogenic properties can be obtained. In vitro, these cells produce branching colonies with both myo- and luminal epithelial cells. The putative stem cells are highly enriched for ER $\alpha$ positive cells. Interestingly, ER $\alpha$-positive stem cells do not transplant in vivo (into mouse mammary fat pads), and furthermore, ER $\alpha$-positive cells do not co-localize with prolifer- ation marker Ki 67 in normal human breast tissue. In contrast, data by Allred et al. [5] and others [6] clearly shows that $\mathrm{ER} \alpha$-positive cells are enriched in premalignant lesions, such as hyperplastic enlarged lobular units (HELU), atypical ductal hyperplasia (ADH) and, most frequently, in IBC. Recent data by Ewan et al. [7] suggests that the proliferation of ER $\alpha$ positive cells is restrained by the transforming growth factor $\beta$ (TGF- $\beta$ ), thus opening prophylactic therapy targets against breast cancer.

In conclusion, a model is proposed in which the ER phenotype of the resulting tumor depends on the original stem cell. Thus, ER $\alpha$-high, -low or -negative phenotypes may occur in tumors depending on the cell from which tumorigenesis originates. Indeed, this model fits well into the genetic subtypes of human breast cancer previously outlined by Sorlie et al.[8]. Charles Perou, PhD (University of North Carolina, Chapel Hill, NC, USA) presented material concerning the 'developmental and therapeutic implications of molecular profiles of ER-positive and ER-negative breast cancers'. Gene expression profiling of IBC carried out by many investigators have identified IBC to be not one, but several distinct diseases. Previous work by this group outlined 4 intrinsic subtypes of IBC [8]: luminal A, luminal B, basal-like, and HER2+/ER-. The luminal A and B subtypes are ER-positive, while the basal-like and HER2+/ER- tumors are both ER- and PgR-negative. Importantly, these subtypes are associated with different clinical outcomes. Current research focuses on 2 major questions: Can the described subtypes be identified in premalignant lesions? And, which are the cellular origins of each subtype? To address the first question, the gene expression profiles of 25 ductal carcinoma in situ (DCIS) samples were analyzed. Indeed, the investigators were able to identify all 4 subtypes within DCIS. Further work will determine whether ER+ luminal subtypes can coexist with basal-like subtypes within a single-patient sample. Moreover, it remains to be elucidated whether ADH (ER+) can coexist with DCIS lesions of the basal-like or HER2+/ ER-subtype.

Concerning the cellular origins of ER-positive and -negative breast cancer, only the luminal subtypes tend to express ER, whereas the other subtypes would correspond to what has previously been described as a hormone receptor (HR)-negative breast cancer. As a starting point of subtype origin studies, morphological criteria were assessed: Luminal and HER2+/ER- subtypes clearly show alveolar features as opposed to the basal-like subtype which has a basal/myoepithelial pattern. Basal-like tumors make up for $10-20 \%$ of breast cancers and have been shown to constitute a poor clinical prognosis. $50 \%$ have mutant $\mathrm{p} 53$, and the expression profile has been observed in BRCA-1-related breast cancer. Concerning immunohistochemical features, basal-like tumors are unique in expressing basal/myoepithelial keratins 5, 6A, 6B, 14 and 17 . Yet, about $50 \%$ of this subtype can co-express luminal keratins 8 and 18. Despite the myoepithelial morphology, 
myoepithelial markers SMA, p63 and CD10 are rare. Thus, basal-like tumors are unlikely to originate from myoepithelial cells. This in conjunction with the expression of proliferation markers, some stem cell markers, epidermal growth factor receptor (EGFR) and vimentin, leads to the hypothesis that this tumor represents a 'transient amplifying' cell that is a committed progenitor with bipotent potential (thus incorporating luminal and myoepithelial features). In-depth studies concerning the phenotypic evaluation of the basal-like subtype have been published online shortly before the meeting [9]. A randomized phase II study including basal-like, stage IV tumor subtypes (characterized by a 'triple negative phenotype' in immunohistochemistry) was announced (LCC 0403). Patients will be randomized to either cetuximab in combination with carboplatin or cetuximab alone. Patients will be allowed to cross over to the combination regimen arm if disease progression occurs. Luminal subtypes express ER and genes regulated by this receptor. Furthermore, luminal A subtype (and less so luminal B) show the androgen receptor and GATA 3 (including genes regulated by GATA3). The expression signature is similar but lower in luminal B versus luminal A cells, and clinical data has demonstrated a more favorable outcome for luminal A tumors.

In conclusion of these data, it can be hypothesized that tumors maintain their genetic profile during the development from DCIS to IBC. The subtypes appear to originate from cells that represent discreet stages of epithelial development or stem cells that stop at a specific stage of development. Luminal A cells thus represent well differentiated alveolar cells, while luminal B and Her2+/ER- subtypes progress from stages between the bipotent progenitors and the alveolar cells. The deregulation of specific pathways necessary for progression from the cell type of origin to the specific tumor subtype need to be further characterized, since they may represent novel therapeutic targets.

Graham Colditz, MD, PhD (Harvard School of Public Health, Boston, MA, USA) reported on ' how epidemiologic risk factors differ according to receptor status of breast cancer'. Past evidence shows historically small studies, with HR analysis limited to either ER-positive or -negative status. Few of these studies used formal statistical comparison before drawing conclusions. Discrepancies between several former studies can be attributed to small sample size and imprecise modeling. The modeling of reproductive risk factors may play a major role. Indeed, the risk of breast cancer decreases after menopause (in contrast to other cancers), and models not incorporating these phenomena have been shown to impact the risk estimation. In order to quantify the effects of each risk factor, a calendar for the specific risk factor was created spanning from menarche to pre-menopause to postmenopause, and effects were summarized according to the calendar (e.g. BMI in premenopause and BMI after menopause).

Previous analysis of risk factors from the Nurses' Health Study [10] indicated that risk profiles may vary according to
HR status. In the extended follow up data since 2004, 2,783 incidents of invasive breast cancer were identified and risk factor analysis was carried out on 1,728 women with $\mathrm{ER}+\mathrm{PgR}+$ tumors, 518 women with ER-/PgR-, 440 women with $\mathrm{ER}+/ \mathrm{PgR}-$ and 97 women with $\mathrm{ER}-/ \mathrm{PgR}+$. A single adverse effect of first pregnancy was reported only for ER+ or HRtumors. The heterogeneity between HR subgroups for the adverse association of first pregnancy with breast cancer incidence was statistically significant. Interestingly, late menopause (age 55 vs. 45 years) was associated with a significant increase in hazard ratio in $\mathrm{ER}+/ \mathrm{PgR}+$ but not in $\mathrm{HR}$ - tumors. Similar observations concerning differential risk profiles between $\mathrm{ER}+/ \mathrm{PgR}+$ and $\mathrm{HR}$ - patients could be made for pregnancy history and postmenopausal hormones. No differences were seen in breast cancer incidence according to HR status for family history and benign breast disease.

In summary, risk models have to be evaluated according to breast cancer subtypes. Simple regression models to estimate risk are insufficient, and polychotomous logistic regression models may be more suitable to fit the data. Epidemiologic risk factors that vary according to HR subtype support the hypothesis that receptor expression categories are stable breast cancer phenotypes.

\section{Poster Presentations on Endocrine Therapy, Hormone Receptor Signaling and Hormone Replacement Therapy}

\section{New data from Antiestrogen Research (Abstracts 4100-4105; $S A B C S$ 2005)}

In the era of aromatase inhibitors (AIs), the focus has shifted away from antiestrogens. However, one must not overlook the fact that in a global perspective, AIs are not affordable to the majority of breast cancer patients or their respective societies. Also, insights into tamoxifen resistance may help to elucidate 'AI resistance' or estrogen hypersensitivity in the future. Shou et al. (abstract 4100) made clear mechanistic statements about previously observed tamoxifen resistance in the clinic. The authors highlight the role of AIB1 phorsphorylation in the mediation of tamoxifen resistance. High levels of both HER2 and AIB1 correlated with disease progression. The authors suggest that blocking the signaling between the 2 players may prevent the onset of clinical tamoxifen resistance. Further preclinical work on resistance to endocrine treatment was presented by MacPherson et al. (abstract 4102). The authors identified a number of genes associated with letrozole resistance. Further work on patient biopsies will validate the genes associated with tamoxifen (prior work) and letrozole resistance. Furthermore, in vitro data concerning genetic changes of MCF-7 cells treated with either trilostane or tamoxifen was presented, focusing on the upregulation of ER $\beta$ and the multidrug resistance gene ABCG2 by trilostane as opposed to tamoxifen (abstract 4104). 
News about Endocrine Therapy (Abstracts 5076-5100; SABCS 2005)

\section{Preclinical Data on Novel Therapeutic Agents}

Abstract 5079 introduced novel data concerning anti-tumor effects of rosiglitazone. Especially in combination with TNF $\alpha$ or $\mathrm{CH} 11$, this ligand of peroxisome proliferators-activated receptor gamma (PPAR $\gamma$ ) can sensitize breast cancer cells cultured in vitro to apoptosis, and synergizes with roscovitine in growth inhibition. Further in vivo work will be needed to provide further evidence of the synergistic interaction of recombinant human insulin growth factor-binding protein 3 (rhIGFBp-3) and letrozole (abstract 5081). Brandy et al. (abstract 5082) presented work describing a role for aromatase inhibition in ER $\alpha$-negative breast cancer. Indeed, the material presented shows inhibition of cancer cell invasion and the in vivo formation of metastasis with letrozole alone or (to a much enhanced degree) in combination with the matrix metalloproteinase (MMP) inhibitor COL-3.

\section{Identification of New Therapeutic Targets}

Abstract 5080 provided new data obtained by gene expression studies of patient tumors under neoadjuvant exemestane with or without tamoxifen. The authors have identified 18 genes altered by estrogen blockade. Using an estrogen-independent xenograft model, Gauri et al. (abstract 5083) provide intriguing evidence that PI3K/Akt pathways in combination with ER $\alpha$ signaling may lead to better control over estrogen-independent tumors. The nuclear receptor LRH-1 regulates the expression of aromatase in the breast. The inhibition of this specific pathway could lead to highly organ-specific aromatase inhibition (abstract 5085).

\section{Clinical Trials}

Young et al. (abstract 5084) reported on a preoperative study randomizing premenopausal women into either fulvestrant or daily tamoxifen 2 weeks before surgery. Both substances reduced ER and PgR expression and Ki 67 and were well tolerated. Two phase II studies (abstracts 5087 and 5098) reported on tipifarnib. Both studies were carried out after antiestrogen therapy in advanced breast cancer, but Johnston et al. combined the study drug with letrozole, while the French study (Dalenc et al.) combined tipifarnib with tamoxifen despite progression under antiestrogens. Interestingly, the combination of letrozole with tipifarnib did not show significant differences towards letrozole and placebo. The investigators combining the antiestrogen with tipifarnib reported a $55 \%$ stable disease + partial remission rate in a population described as progressive before study inclusion. Initial data on TAS-108, a steroidal antiestrogen, was reported from a phase I trial presented by Noguchi et al. (abstract 5091). Abstract 5095 was presented by Chow et al. and reported on a proof-of-principle study combining aromatase inhibition with COX-2 inhibitors in locally advanced breast cancer. The authors concluded that indeed the clinical addition of celecoxib may provide additional benefit.

\section{Drug Metabolism and Side Effects of Endocrine Therapies}

Gjerde et al. (abstract 5086) reported on a novel explanation concerning inter-patient variation of tamoxifen serum levels. They identified polymorphisms in CYP2D6 and SULT1A1 and showed a clear influence on the tamoxifen metabolism. Further data on drug metabolism was presented by Desta et al. (abstract 5090) who have identified CYP3A to be a major catalyst. The Intergroup Exemestane Study (IES) Group reported on data form their bone mineral density (BMD) subprotocol (abstract 5076). The IES group is now able to report on 206 patients with up to 24 months follow-up. After 6 months of stopping tamoxifen and starting exemestane, significant changes in bone markers and BMD occur. The authors concluded that this is most likely due to the lack of bone turnover suppression mediated by tamoxifen. After the switch, the BMD loss per year was $<1 \%$, thus less than data previously reported with other aromatase inhibitors. There was no significant difference between the switch group and the 5-year tamoxifen group.

\section{Estrogen and Progestin Receptor Signaling (Abstracts 5101-5114; SABCS 2005)}

Several presentations focused on novel data concerning ER signaling. Data reported in abstract 5103 focused on estrogenmediated suppression of gene expression in treated MCF-7 cells. In summary, the authors presented the cell cycle regulators Btg2, Jun B and, interestingly, TGF $\beta$ (previously reported as an antiproliferative factor) to be downregulated after estrogen treatment in vitro. Two presentations by Oesterreich et al. (abstract 5105) focused on ER $\alpha$ co-repressors. The group has previously identified and cloned scaffold attachment factor B1 (SAFB1) and now report that depletion leads to increased $\mathrm{ER} \alpha$ signaling and potentially tumorigenesis. In their second report (abstract 5108), the authors contributed a table of 236 genes repressed by estrogen. An intriguing clinical report came from Thor et al. (abstract 5106), containing preclinical and clinical data suggesting that thyroid hormone intake may have negative effects on disease-free survival and disease-specific overall survival in breast cancer patients. Two abstracts (5109 and 5111) made similar observations concerning the expression of ER $\beta$ and predicted hormonal responsiveness to tamoxifen. Their data suggest that low ER $\beta$ expression may predict tamoxifen resistance.

\section{Tamoxifen and Hormone Replacement Therapy (Abstracts 19, 6043-6049; SABCS 2005)}

According to data from the IBIS-1 trial, it is now clear that women still suffer from significantly more hot flashes after 
84 months of follow-up when treated with tamoxifen. Especially severe hot flashes double from 6.6 to $12.2 \%$ in the treatment arm. If symptoms persisted at 12 months, hormone replacement therapy reduced vasomotor symptoms in the placebo arm, but unfortunately not in the tamoxifen arm. The authors hypothesize that the phenomenon may be due to a saturation of ER by the study drug. Future studies should certainly investigate alternative approaches to alleviating vasomotor symptoms caused by tamoxifen.

\section{References}

1 Reya T, Clevers H: Wnt signalling in stem cells and cancer. Nature 2005;434:843-850.

2 Reya T, Morrison SJ, Clarke MF, Weissman IL Stem cells, cancer, and cancer stem cells. Nature 2001;414:105-111.

3 Clarke RB: Isolation and characterization of human mammary stem cells. Cell Prolif 2005;38: 375-386.

4 Smalley MJ, Clarke RB: The mammary gland 'side population': a putative stem/progenitor cell marker? J Mammary Gland Biol Neoplasia 2005;10: $37-47$.

5 Allred DC, Brown P, Medina D: The origins of estrogen receptor alpha-positive and estrogen receptor alpha-negative human breast cancer. Breast Cancer Res 2004;6:240-245.
Shoker BS, Jarvis C, Clarke RB, Anderson E, Hewlett J, Davies MP, Sibson DR, Sloane JP: Estrogen receptor-positive proliferating cells in the normal and precancerous breast. Am J Pathol 1999; 155:1811-1815.

7 Ewan KB, Oketch-Rabah HA, Ravani SA, Shyamala G, Moses HL, Barcellos-Hoff MH: Proliferation of estrogen receptor-alpha-positive mammary epithelial cells is restrained by transforming growth factor-beta1 in adult mice. Am J Pathol 2005;167: 409-417.
Sorlie T, Tibshirani R, Parker J, Hastie T, Marron JS, Nobel A, Deng S, Johnsen H, Pesich R, Geisler $\mathrm{S}$, Demeter J, Perou CM, Lonning PE, Brown PO, Borresen-Dale AL, Botstein D: Repeated observation of breast tumor subtypes in independent gene expression data sets. Proc Natl Acad Sci U S A 2003;100:8418-8423.

9 Livasy CA, Karaca G, Nanda R, Tretiakova MS Olopade OI, Moore DT, Perou CM: Phenotypic evaluation of the basal-like subtype of invasive breast carcinoma. Mod Pathol 2006;19:264-271.

-10 Colditz GA, Rosner BA, Chen WY, Holmes MD, Hankinson SE: Risk factors for breast cancer according to estrogen and progesterone receptor status. J Natl Cancer Inst 2004;96:218-228. 